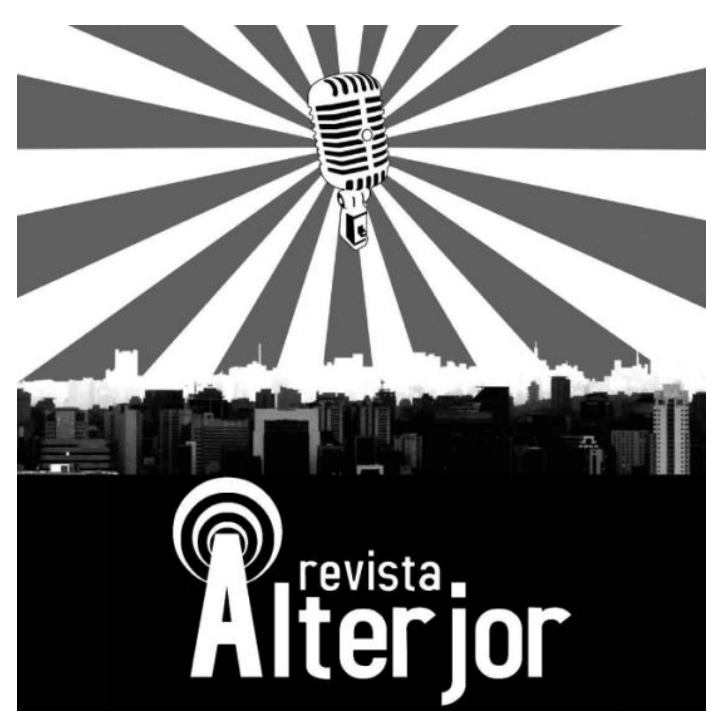

\title{
CONTANDO HISTÓRIA ATRAVÉS DE ESTÓRIA: PROCESSO ESTORICIZANTE E O STORYTELLING COMO FORMA ALTERNATIVA DE TRANSMISSÃO DE FATOS HISTÓRICOS
}

\author{
Rafael Duarte Oliveira Venancio ${ }^{1}$
}

RESUMO: O presente artigo deseja refletir acerca da condição da ficção histórica como forma alternativa de contar a História através de ficção, ou seja, de estórias. A partir de um debate acerca da tradição do storytelling e de suas possíveis tensões com a historiografia, há aqui a construção de um conceito teórico de nossa autoria: o processo estoricizante. Assim, o artigo se propõe tanto a definir o conceito, demonstrar sua existência em uma tradição brasileira e internacional de transmissão de fatos históricos, seja no jornalismo seja na literatura, bem como destacar algumas produções, inclusive do próprio autor que desenvolve pós-doutorado sobre o tema.

PALAVRAS-CHAVE: Storytelling, Historiografia, Narrativa, Comunicação Alternativa, Ficção Histórica.

ABSTRACT: This article seeks to reflect on the condition of historical fiction as an alternative way of telling History through fiction, that is, through stories. From a debate about the tradition of storytelling and its possible tensions with historiography, there is the construction of a theoretical concept of our authorship: the storicizing process. Thus, the article proposes to define the concept, to demonstrate its existence in a Brazilian and international tradition of transmitting historical facts, whether in journalism or literature, as well as to highlight some productions, including from the author himself who develops postdoctoral studies on the theme.

KEYWORDS: Storytelling, Historiography, Narrative, Alternative Communication, Historical Fiction.

\footnotetext{
Pós-doutorando do Departamento de Cinema, Rádio e Televisão e Doutor em Meios e Processos Audiovisuais, ambos pela Escola de Comunicações e Artes da Universidade de São Paulo (ECA-USP).
}

Revista ALTERJOR

Grupo de Estudos Alterjor:Jornalismo Popular e Alternativo (ECA-USP)

Ano 10 Volume 02 Edição $22 \quad$ Juho-Dezembro de 2020

Avenida Professor Lúcio Martins Rodriģues, 443, Cidade Universitária, São Paulo, CEP: 05508-020 


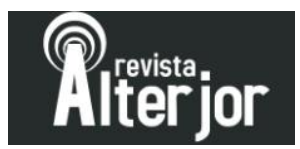

\section{Introdução}

A reflexão da relação entre história e estória, mesmo com a palavra com E inicial ter sido retirada do vocabulário oficial da língua portuguesa, é algo que permeia o debate da literatura, da comunicação e jornalismo, bem como da própria história feita no Brasil. Encontramos sinais disso nos nossos pais fundadores das Letras Brasileiras, tal como Machado de Assis:

E repare o leitor como a língua portuguesa é engenhosa. Um contador de histórias é justamente o contrário de historiador, não sendo um historiador, afinal de contas, mais do que um contador de histórias. Por quê essa diferença? Simples, leitor, nada mais simples. O historiador foi inventado por ti, homem culto, letrado humanista; o contador de histórias foi inventado pelo povo, que nunca leu Tito Lívio, e entende que contar o que se passou é só fantasiar (ASSIS, 1994).

Machado de Assis não poderia ter sido mais claro. Apesar do historiador se tensionar acerca com a noção de estória, a contação de estórias e a ficção histórica estão longe de serem estrangeiras a ela. Muito menos opostas. No entanto, como isso seria possível?

Para o autor do presente artigo, a estória se vincula como forma alternativa de transmitir fatos históricos - considerando que a historiografia e a História são a forma "oficial" - a partir de um processo narrativo que denominamos de processo estoricizante.

O objetivo do presente artigo é definir o conceito de processo estoricizante, demonstrar sua existência em uma tradição brasileira e internacional de transmissão de fatos históricos, seja no jornalismo seja na literatura, bem como destacar algumas produções, inclusive do próprio autor que desenvolve pós-doutorado sobre o tema ${ }^{2}$.

\footnotetext{
${ }^{2}$ Projeto "FUTEBOL NÃO É SÓ NO GRAMADO: A narrativa no radiodrama esportivo de Estevam Sangirardi", sob a supervisão do Prof. Dr. Eduardo Vicente, no Departamento de Cinema, Rádio e Televisão da Escola de Comunicações e Artes da Universidade de São Paulo com vigência entre $1^{\circ}$ de fevereiro de 2019 a $1^{\circ}$ de agosto de 2020.
} 


\section{Preiejer}

Assim, será possível jogar uma luz conceitual sobre o tema das "estórias" enquanto forma de "História", buscando uma expansão da literacia e do conhecimento histórico do brasileiro, de demais lusófonos e, até mesmo, globalmente.

\section{Historiografia, Jornalismo e Ficção Histórica}

A questão sobre a definição de História, em si, já é objeto de inúmeros artigos científicos, ensaios, livros e, até mesmo, a obra completa de pesquisadores das mais diversas épocas. Uma dessas definições que nos chama atenção é aquela desenvolvida por E. H. Carr e apresentada em suas conferências ${ }^{3}$ sobre “Que é História?”:

Quando tentemos responder à pergunta "Que é história?" nossa resposta, consciente ou inconscientemente reflete nossa própria posição no tempo, e faz parte da nossa resposta a uma pergunta mais ampla: que visão nós temos da sociedade em que vivemos? (CARR, 2011)

Assim, para Carr, a História está diretamente vinculada com a atividade do

historiador e da escrita da História, denominada historiografia:

A relação entre o historiador e seus fatos é de igualdade e de reciprocidade. Como qualquer historiador ativo sabe, se ele pára para avaliar o que está fazendo enquanto pensa e escreve, o historiador entra num processo contínuo de moldar seus fatos segundo sua interpretação e sua interpretação segundo seus fatos. É impossível determinar a primazia de um sobre o outro.

O historiador começa com uma seleção provisória de fatos e uma interpretação também provisória, a partir da qual a seleção foi feita tanto pelos outros quanto por ele mesmo. Enquanto trabalha, tanto a interpretação e a seleção quanto a ordenação de fatos passam por mudanças sutis e talvez parcialmente inconscientes, através da ação recíproca de uma ou da outra. Essa ação mútua também envolve a reciprocidade entre presente e passado, uma vez que o historiador faz parte do presente e os fatos pertencem ao passado.

\footnotetext{
${ }^{3}$ Conferências George Macaulay Trevelyan proferidas por E. H. Carr na Universidade de Cambridge, janeiro-março de 1961.
} 
O historiador e os fatos históricos são necessários um ao outro. $\mathrm{O}$ historiador sem seus fatos não tem raízes e é inútil; os fatos sem seu historiador são mortos e sem significado. Portanto, minha primeira resposta à pergunta "Que é história?" é que ela se constitui de um processo contínuo de interação entre o historiador e seus fatos, um diálogo interminável entre o presente e o passado. (CARR, 2011)

No desenvolvimento do seu raciocínio para chegar nesta definição, Carr passa por um autor que é de importante interesse para o assunto trabalhado no presente artigo:

Collingwood, o único pensador britânico no século atual que fez uma abalizada contribuição à filosofia da história, (...) não viveu o suficiente para escrever a exposição sistemática que planejou; mas seus artigos publicados e notas não publicadas sobre o assunto foram reunidos, após sua morte, num volume intitulado The idea of history, editado em 1945.

As opiniões de Collingwood podem ser reunidas como se segue. A filosofia da história não é relacionada com "o passado em si" nem com "o pensamento do historiador sobre o passado em si mesmo", mas com "as duas coisas em suas relações mútuas". (Esta opinião reflete os dois significados correntes da palavra "história" - a pesquisa conduzida pelo historiador e as séries de acontecimentos passados em que ele investiga.)

"O passado que o historiador estuda não é um passado morto mas um passado que, em algum sentido, está ainda vivo no presente." Mas um ato passado está morto, isto é, sem significado para o historiador, a menos que ele possa apreender o pensamento que está por trás deste passado, desde que "toda história é a história do pensamento" e "a história é a revalidação da mente do historiador do pensamento cuja história ele está estudando".

A reconstituição do passado na mente do historiador está na dependência da evidência empírica. Mas não é em si mesmo um processo empírico e não pode consistir de uma mera narração de fatos. Ao contrário, o processo de reconstituição governa a seleção e interpretação dos fatos: isto, aliás, é o que faz deles fatos históricos. (CARR, 2011)

Collingwood coloca a historiografia enquanto uma capacidade de escrita e reconstrução onde os fatos históricos são os fatos do passado que o historiador diretamente seleciona, interpreta e dá uma forma narrativa que faz surgir o texto 


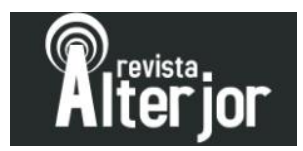

histórico. Isso faz vincular a atividade do historiador com, por exemplo, a do jornalista. A escrita jornalística nada mais é que uma capacidade de escrita e reconstrução onde os fatos jornalísticos (noticiosos) são os fatos do presente que o jornalista diretamente seleciona, interpreta e dá uma forma narrativa que faz surgir o texto jornalístico (notícias, reportagens).

E o escritor literário? E quando ele usa os fatos do passado para o texto literário? A chamada ficção histórica? O que acontece? O uso de imaginações, personagens ficcionais interagindo com personagens reais e outras fabulações transforma a ficção histórica enquanto uma opositora à História. Algo semelhante que, curiosamente, a História acha do Jornalismo. Enquanto os historiadores criticam os jornalistas por escreverem ao sabor do presente, os mesmos historiadores criticam os escritores literários por escreverem ao sabor do estilo, da fabulação e de tudo mais que pode entrar na noção de ficção vista enquanto refabricação da realidade pelo imaginário e imaginação.

Assim, à luz das ideias de Carr e Collingwood, podemos pensar a ficção histórica sob nova vertente. Pela noção de narrativa e de storytelling. Eis assim o advento do conceito teórico de processo estoricizante.

\section{Storytelling, Narrativa e o Processo estoricizante}

Dentro do escopo do pós-doutorado no qual o presente texto se insere, estamos aqui em um campo epistemológico denominado Narratologia, onde há o estudo da narrativa. Assim, pensando no mundo da narrativa e do storytelling, a ficção histórica pode ser construída a partir de algo que denominamos enquanto processo estoricizante. Aqui a palavra é estoricizante de estória com E inicial, para distinguir do conceito de processo historicizante da historiografia e da história com $\mathrm{H}$ inicial.

A palavra estória, com E inicial, representa a tradução possível do inglês story, que indica as narrativas que necessariamente não são históricas, englobando algum grau seja de ficção, seja de subjetividade ou mesmo de imaginação. 


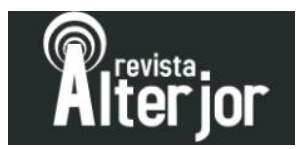

Deste modo, o processo estoricizante seria você observar os fatos da história e fazer uma estória. Há quem diga que isso já é englobado pela conceituação do gênero literário denominado ficção histórica. De certo modo, é isso. No entanto, o processo estoricizante demarca uma particularidade dentro do amplo gênero da ficção histórica. Ela, necessariamente, é uma forma de storytelling, ou seja, de narrativização a partir do conceito de "contação de histórias".

Isso faz que com essa ideia, desenvolvida pelo presente pós-doutorado, de processo estoricizante se insira no campo dos estudos do Storytelling que, para muitos, foi fundado por Walter Benjamin (1994) e seu texto "O Narrador" que, em inglês, é chamado de "The Storyteller", ou seja, "O Contador de Histórias".

Há aqui uma definição, de nossa lavra, de storytelling:

Storytelling, tal como diegese, é alvo de inúmeras definições acadêmicas. No entanto, o termo é mais recente em tais círculos e não possui uma tradição consolidada. De minha lavra e de maneira resumida, defino storytelling como a práxis da narrativa a partir de sua relação locucional, sendo locução aqui o conjunto de formas de uso linguístico que normalmente chamamos de contação, diálogo, narração, entre outras. Assim, o storytelling não é uma atividade descritiva - ou seja, usar as palavras para descrever as coisas -, muito menos uma atividade dissertativa - ou seja, usar as palavras para dissertar, dar opiniões. Storytelling é uma atividade de contar uma história a partir de locução feita por personagens (VENANCIO, 2019a, p. 14-15).

Posto este arcabouço teórico inicial, podemos fazer algumas considerações sobre o processo estoricizante e seu agente criador, o storyteller (contador de estórias).

A primeira é que enquanto o historiador olha para o passado em uma forma mais bruta (documentos, provas), o storyteller olha para a história mesmo, para o trabalho de historiadores. Assim, podemos dizer que o processo estoricizante é uma leitura da historiografia.

Já a segunda é que o storyteller precisa responder muito mais diretamente às questões do tempo presente do que o próprio historiador. Nisso, ele se assemelha ao jornalista. Sua função enquanto artista da palavra possui um compromisso e uma ação 


\section{Preitior}

na esfera pública. Assim, podemos dizer que o processo estoricizante busca informar, debater, formar opiniões dentro e fora do mundo do jornalismo.

A terceira é que o storyteller, acima de tudo, é um escritor e pode ser visto enquanto um escritor literário. Sua atividade de fabulação e imaginação, resumida na capacidade de ficcionalizar para criar o texto da estória, o possibilita colocar no rol da literatura. Assim, podemos dizer que o processo estoricizante é um gênero da literatura, muitas vezes denominado ficção histórica. No entanto, enquanto todo processo estoricizante é uma ficção histórica, o oposto não é verdadeiro, pois há literatura enquadrada neste gênero que não cumpre as outras considerações que compõem o processo estoricizante.

Por fim, a quarta e última, pelo menos no presente texto, é que o processo estoricizante por ser storytelling, é uma atividade performativa da palavra ("contar" estórias). Assim, ela se assemelha com a dramaturgia, seu uso dos diálogos e a atividade do uso da linguagem baseado no registro oral. Assim, podemos dizer que o processo estoricizante performa o conteúdo histórico.

Assim, podemos aplicar no processo estoricizante a construção inspirada em

Collingwood que mencionamos anteriormente. O processo estoricizante pode ser visto enquanto uma capacidade de escrita e reconstrução onde os fatos da estória são os fatos históricos que o storyteller diretamente seleciona, interpreta e dá uma forma narrativa, mesclando estratégias jornalísticas, literárias e dramatúrgicas, que faz surgir o texto da estória.

\section{Exemplos de uso na literatura e no jornalismo}

Tendo a reflexão posta em vista, podemos apontar alguns exemplos de uso, normalmente identificados enquanto literatura e/ou jornalismo, do processo estoricizante.

$\mathrm{Na}$ literatura, há muitos exemplos que eu poderia elencar aqui. Do mundo atual de best sellers, Bernard Cornwell parece ser aquele que melhor executa os elementos do 
processo estoricizante. Em uma entrevista intitulada Quão Histórica é a Ficção

Histórica?, o escritor inglês nos diz que

se o romance não é histórico, não é ficção histórica! O que isso significa para mim é que qualquer romance histórico tenta oferecer ao leitor uma imagem de outra época e tenta tornar essa imagem o mais precisa possível. Escritores criam mundos, e o mundo de um romancista histórico é o passado! Tenho certeza de que não acertamos a maior parte do tempo, mas ainda assim o pano de fundo da história deve evocar uma era antiga para o leitor (...) Então o mundo de fundo tem que ser o mais preciso possível, independentemente do que está acontecendo na história (...) Lembre-se que eu não sou historiador. Não estou aqui para ensinar história anglo-saxônica ou qualquer outra história. Eu sou um contador de histórias, então minha primeira responsabilidade é contar uma história! Essa história é ficção, mesmo que seja baseada em um episódio conhecido da história. Portanto, precisão e autenticidade devem ficar em segundo lugar na história. Obviamente, há um limite para isso; um escritor de ficção não consegue se safar ao deixar os franceses vencerem na batalha de Waterloo... Se ele faz isso, deixa de ser um romance histórico e se torna um romance de fantasia. Mas todos fazemos mudanças. (...) Eu leio livros! Eu visito os lugares! Eu compro livros! Eu leio mais! (...) Sou muito grato a todos os acadêmicos maravilhosos que fazem a pesquisa original que eu uso, mas existem vastas áreas da vida que não são cobertas pela academia... os pequenos detalhes da vida. Alguns dos melhores materiais vêm dos lugares mais estranhos e outros vêm inteiramente da imaginação! (CORNWELL, 2019).

Assim, Cornwell se coloca como a ponta mais contemporânea de uma longa

linhagem de autores britânicos que usaram isso que podemos chamar de processo estoricizante na literatura. O mais importante de todos, inclusive, é um dramaturgo:

William Shakespeare, que viveu entre 1564 e 1616, escrevendo estórias de duzentos anos antes:

Não foi Shakespeare, mas os estudiosos de Shakespeare, que categorizam suas peças nas áreas de tragédia, comédia e história. (...) As peças normalmente referidas como peças de história de Shakespeare são as dez peças que cobrem a história inglesa dos séculos XII a XVI, e o período 1399-1485 em particular. Cada peça histórica recebe o nome e se concentra no monarca reinante do período (...). Nunca devemos esquecer que são obras de imaginação, baseadas muito vagamente em figuras históricas. Shakespeare era um ávido leitor de história e estava sempre procurando o impacto dramático de personagens e eventos históricos enquanto lia. Hoje, 
tendemos a pensar nessas figuras históricas da maneira que Shakespeare as apresentou. Por exemplo, pensamos em Richard III como um homem mau, uma espécie de psicopata com corpo deformado e ressentimento contra a humanidade. Os historiadores podem fazer o que bem entenderem, mas o Richard de Shakespeare parece preso em nossa cultura como o verdadeiro Richard III. (...) As peças da história são extremamente atraentes. Eles não apenas dão uma idéia dos processos políticos da política medieval e renascentista, mas também oferecem um vislumbre da vida, do alto ao fundo da sociedade - a corte real, a nobreza, a vida nas tavernas, bordéis, mendigos, tudo (KING; KING, 2004).

E no Brasil? Bom, Machado de Assis foi mencionado em nossa introdução. No entanto, há um nome que está nos três campos - a relembrar, jornalismo, literatura e dramaturgia - que o processo estoricizante busca estratégias para ler a historiografia.

Seu nome? Nelson Rodrigues.

Em estudo anterior nosso (VENANCIO, 2014), mostramos que Nelson Rodrigues - famoso pelo seu teatro, pelos seus romances e contos, pelas suas crônicas de jornalismo diário (A Vida como ela é) e pelas suas crônicas esportivas - utilizava abertamente características daquilo que aqui denominamos de processo estoricizante. Aliás, o próprio Nelson afirmava que isso era a essência do bom jornalismo:

A arte jornalística consiste em pentear ou desgrenhar o acontecimento, $\mathrm{e}$, de qualquer forma, negar a sua imagem autêntica e alvar. Modelo de eficiência profissional foi aquele repórter que viu um incêndio (...). O jornalista espia o fogo e conclui que se tratava, na verdade, de um incêndio vagabundo, uma vergonha de incêndio. Qualquer mãe de família o apagaria com um humilhante regador de jardim. Volta o repórter para a redação e, lá, escreve uma página de jornal sobre o fracassado sinistro. E mais: - põe um canário inventado no meio das labaredas, um canário que morre cantando. No dia seguinte, a edição esgotou-se. A cidade inteira, de ponta a ponta, chorou a irreparável perda do bicho. Vejam vocês a lição de vida e de jornalismo: - com duas mentiras, o repórter alcançara um admirável resultado poético e dramático (...). Sem passarinho, não há jornalismo possível (RODRIGUES, 1994, p. 12).

Nelson Rodrigues ia além. Não só fazia isso em sua atividade jornalística, mas também criticava quem não fazia em sua coluna nos jornais: 
Ora, faltou, justamente à vitória gaúcha, o seu poeta. Os correspondentes brasileiros, que estavam no México, deviam mandar, de lá, telegramas rimados, ungidos de histerismo cívico. Mas como estamos em crise de Bilacs, o fabuloso triunfo só inspirou mesmo uma pífia correspondência, que nos enche de humilhação patriótica e vergonha profissional. Cada cronista da delegação, em vez de babar materialmente de gozo, mandou dizer ao seu jornal o seguinte: - "que os argentinos jogaram mais, que os argentinos mereceram vencer e que os brasileiros estavam apáticos". Vejam vocês em que dá a mania da justiça e da objetividade! Um cronista apaixonado havia de retocar o fato, transfigurá-lo, dramatizá-lo. Daria à estúpida e chata realidade um sopro de fantasia (RODRIGUES, 1994, p. 11).

Para nós, outro grande exemplo do processo estoricizante no jornalismo esportivo, porém em mídia distinta daquela do jornal impresso/jornalismo escrito, é o Show de Rádio (1969-1994). Estevam Sangirardi fez um processo estoricizante em seu Show de Rádio porque ele contou, usando radiodrama movido por personagens que são mascotes sonoros arquetípicos dos times de futebol de São Paulo, os fatos ocorridos no jogo de futebol que acabara de acontecer. No entanto, o que é o Show de Rádio?

Em 1965, a Rádio Panamericana, sob o comando de Tuta (Antônio Augusto Amaral de Carvalho), vira Rádio Jovem Pan em busca de uma modernização de sua linguagem. Neste contexto, a Rádio Panamericana, que disputava com a Rádio Bandeirantes a posição de rádio dos esportes, buscava enquanto Jovem Pan um novo domínio. É neste contexto que surge o Show de Rádio em 1969:

A metalinguagem no rádio ressurgiu na década de 1970 com o programa "Show de Rádio", comandado pelo veterano radialista Estevam Sangirardi, que estreou como "Show do Intervalo" (CORAUCCI, 2006: 107) durante as transmissões esportivas da Rádio Jovem Pan, emissora paulista dedicada aos esportes, que visava ampliar a audiência. Como o programa "PRK-30", o "Show de Rádio" tinha início com a interferência da fictícia Rádio Camanducaia na transmissão da emissora. Os humoristas (entre eles Serginho Leite e Nelson Tatá Alexandre) parodiavam outros radialistas (como Osmar Santos e Fausto Silva), faziam as vozes de personagens que representavam os principais times de futebol (o milionário Didu Morumbi, torcedor do São Paulo, os corintianos Joca e Nega, os palmeirenses Noninha e Comendador Fumagalli e os santistas Lança Chamas e Zé das Docas) e imitavam personalidades da política (CARDOSO \& SANTOS, 2012, p. 6-7). 


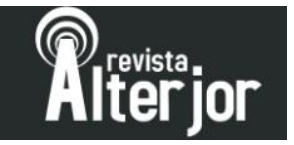

No entanto, a citação anterior não faz jus à complexidade do trabalho de Show de Rádio. Eram programas que chegavam a mais de hora de duração, com roteiro elaborado entre músicas, ficções seriadas e especiais. Um esquete especial famoso era o "programa de Natal” do Show de Rádio, época de fim de campeonatos e de celebração (ou autocrítica) esportiva. Neste programa, em fórmula similar aos programas que tivemos acesso prévio, a ação dramática se passa na casa de Didu Morumbi, o abastado torcedor do São Paulo Futebol Clube, ou melhor "Saint Paul de mon petit coeur" tal como ele dizia. Nisso, Didu e seu mordomo Archibald recebiam as demais personagensmascotes, chamadas aqui de "mascotes sonoros", do Show de Rádio mais versões ficcionalizadas de jornalistas, políticos e jogadores de futebol.

Em datas comemorativas, por exemplo, o programa apresentava pequenos quadros musicais com os mascotes sonoros, apresentando músicas que exaltavam a memória de antigos craques. Um exemplo é o mascote sonoro corinthiano Joca que, em determinado esquete, se lembra, durante sua tradicional conversa com São Jorge, do samba "Gol de Baltazar", de autoria de Alfredo Borba e cantado no carnaval paulistano da primeira metade dos anos 1950 por Elza Laranjeira.

Além disso, para marcar títulos importantes, programas do Show de Rádio eram lançados em vinil, tal como o do campeonato paulista de 1977 quando o Corinthians foi campeão após um jejum de 23 anos, bem como do São Paulo campeão brasileiro de 1978 e o Corinthians campeão paulista de 1982. Nestes LPs, encontramos os programas do Show de Rádio que eram veiculados depois das partidas, tal como se fossem compactos do jogo, onde a interação ficcional dos personagens era entrecortada com os melhores lances.

O pós-doutorado do presente autor, o qual o presente artigo se coloca enquanto produção científica, analisa como Estevam Sangirardi constrói em seu Show de Rádio (1969-1994) um rádio de autor que transita entre a ficção, o humor e o esporte radiofônicos. Com o mote posto em verso pelo jingle de abertura do Show de Rádio que afirma que "futebol não é só no gramado", é buscado demonstrar que Estevam Sangirardi e equipe desenvolvem uma narrativa em teia, com personagens e mundos 


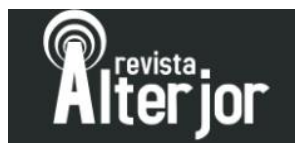

possíveis, urdindo elementos performativos na tradição humorística do rádio brasileiro, na cena radiodramática paulistana, na comunicação esportiva e no futebol em si.

Assim, Estevam Sangirardi construiu um rádio de autor que coloca o futebol enquanto centralidade de uma urdidura ficcional que trabalha o real, o verossímil, o imaginado e o inventado sem distinções, trabalhando com uma diegese que dialogava com o mundo factual, sem necessariamente se misturar a ele.

O funcionamento de sitcom em Show de Rádio nos parece claro. O que temos aqui são os mascotes sonoros dos clubes enquanto personagens e eles vão interagindo com os fatos do futebol do mundo factual (jogo em si) bem como fatos de seu mundo diegético (a relação entre os mascotes sonoros, por exemplo).

Ora, algumas vezes, o Show de Rádio era transmitido no intervalo, contando as interações dos personagens sobre os eventos do primeiro tempo. Era uma maneira dinâmica de fazer rádio esportivo e, especialmente, fazer jornalismo esportivo que estava dentro das tradições postas pela comunicação futebolística brasileira. Assim, é possível afirmar que Estevam Sangirardi e equipe foram para o rádio, o que Thomaz Mazzoni, Nelson Rodrigues, Armando Nogueira e José Roberto Torero foram para o texto escrito de futebol. São todos grandes exemplos do que normalmente chamamos de "cronistas esportivos", tal como foi analisado em trabalhos anteriores (VENANCIO, 2018), e isso é uma das marcas de "rádio de autor" de Estevam Sangirardi.

E como é feito esse processo estoricizante? Bom, a ideia do processo estoricizante é buscar um fato histórico e torná-lo estória através de storytelling. No Show de Rádio, ele normalmente era posto em uma lógica triangular. Um determinado jogo de futebol (normalmente, o jogo da transmissão esportiva do dia) e um clube de futebol paulista são escolhidos e possuem sua história transformada em estória por um personagem na forma radiofônica de monólogo, solilóquio ou mesmo diálogo, onde um dos personagens claramente é uma "escada", um apoio, tal como as servas e os escudeiros nas tragédias gregas de Ésquilo, Sófocles e Eurípides ou mesmo nos textos teatrais de Shakespeare e Racine. 


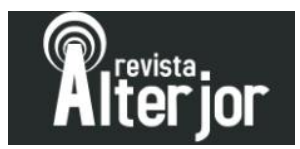

Assim, há um personagem, que é o agente da estória, é uma espécie de mascote sonoro do clube de futebol escolhido. Em uma primeira visão, poderíamos chamar esses personagens, os mascotes sonoros, enquanto estereótipos esportivos de torcedores. Somos da opinião, baseada em Jung (2019), que esses mascotes sonoros são, na verdade, arquétipos, assunto esse desenvolvido em outro artigo (VENANCIO, 2020).

Por fim, o próprio autor do presente artigo possui produções que possuem a ideia de processo estoricizante na construção de sua diegese e narrativa desde 2016. A primeira dessas produções ficcionais foi o romance Aposte no Mossoró, de 2016:

\begin{abstract}
Ao encontrar uma garrafa velha na garagem do seu avô, Raul entra em uma aventura pelos fatos esportivos que ocorreram no Rio de Janeiro de 1933. Seguindo as histórias dos moradores do bairro de Bangu, ele vive os feitos do cavalo Mossoró, da criação do futebol profissional e do envolvimento do Bangu Atlético Clube nesse processo, bem como as primeiras corridas internacionais de automobilismo realizadas no Brasil. O livro Aposte no Mossoró: Uma estória esportiva no Rio de Janeiro dos anos 1930 é um romance histórico escrito para jovens que vivem em uma geração de linguagem rápida, direta e concisa. Favorecendo o diálogo, a ficção construída por Rafael Duarte Oliveira Venancio demonstra que é possível fazer contar a história através de estórias que demarcam mais o conteúdo vivido por pessoas do que a descrição dura. Além disso, o livro demonstra uma importante iniciativa na recuperação da memória esportiva do Brasil onde o imediatismo parece vencer. Ao falar de turfe, de futebol e de automobilismo, Aposte no Mossoró acaba contando um pouco sobre como era viver nos anos 1930 e entender as paixões compartilhadas por quem viveu naquele tempo (VENANCIO, 2016).
\end{abstract}

Depois vieram as peças teatrais em 2017, com destaque para Pilotos em uma

Curva: Monólogo teatral sobre automobilismo que ganhou uma leitura na Rádio USP

FM na Série Biografias Sonoras do Programa Universidade 93.7 em 2020:

$\mathrm{Na}$ chamada era dourada do automobilismo, a figura maior das pistas vive o seu último grand prix antes da sua aposentadoria, dividindo o dia entre memórias, tristezas presentes e futuros incertos. Através de um único narrador, acompanhamos diversos pilotos realizarem curvas metafóricas (ou não) em suas vidas. Com esse monólogo teatral adaptado de duas obras de sua autoria, Rafael Duarte Oliveira Venancio desenvolve uma peça de teatro com tons inspirados na

Revista ALTERJOR

Grupo de Estudos Alterjor:Jornalismo Popular e Alternativo (ECA-USP)

Ano 10 Volume 02 Edição $22 \quad$ Juho- Dezembro de 2020

Avenida Professor Lúcio Martins Rodrig̉ues, 443, Cidade Universitária, São Paulo, CEP: 05508-020 


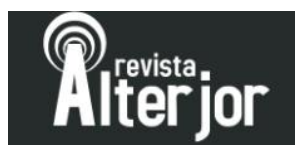

dramaturgia de Samuel Beckett baseada nas carreiras de Juan Manuel Fangio, Luigi Musso, Mike Hawthorn, Stirling Moss, Jean-Pierre Wimille e outros. É uma viagem no mundo do automobilismo que vai do começo dos anos 1930 até o finzinho dos anos 1950 (VENANCIO, 2017).

Depois, vieram as coleções de microcontos em 2018 e 2019: a Microcontos da Copa do Mundo, Abecedário de Craques e Microcontos da Copa América. Tal como foi relatado pelo site do Globo Esporte no contexto do lançamento da primeira coleção:

Futebol, literatura e Copa do Mundo. Tentando resgatar um gênero textual perdido na crônica esportiva, um jornalista e professor da Universidade Federal de Uberlândia (UFU) iniciou uma empreitada como ele mesmo definiu - para recontar de forma diferente todos os jogos de Copa do Mundo até 2018. Baseado no gênero ficcional do conto, o microconto, como o trecho que abre esta reportagem, Rafael Duarte Oliveira Venancio reconta, em 100 palavras, cada partida realizada nos Mundiais da Fifa. Com 20 obras publicadas, a 21 a, sobre a Copa do Mundo da Rússia, que começa nesta quinta-feira, será a primeira escrita em tempo real.

Misturando realidade e ficção, cada uma das 20 edições resultou em um livro em versão impressa e digital, com maneiras diversas para recontar e extrair o melhor de cada jogo. Rafael Duarte usa diálogos, pensamentos, ficção, flashbacks e outros recursos narrativos para atingir qualquer público.

- Existem diferentes formas de falar de futebol: sobre o jogo, sobre os números do jogo, e por que não podemos falar com o olhar mais solto da fabulação? Como contos, prosas, conversas, que é comum do brasileiro. Às vezes, perdemos isso. A ideia de trazer isso para falar de futebol, e de uma competição como a Copa do Mundo, é um jeito de pegar competições grandes e ter uma pequena história de cada jogo. Quem conhece muito sobre futebol, vai ver uma coisa diferente. Quem não conhece nada sobre Copa ou aquela época, aprende um pouco mais - disse (PAPEL, 2018, s/n).

Em 2019, também veio, dentro da ideia de processo estoricizante, O Dançarino e o Húngaro: Uma estória são-paulina do futebol dos anos 1950, um segundo romance de ficção histórica de futebol:

Últimos dias de dezembro de 1957, um jovem jornalista encontra uma crônica incompleta na máquina de escrever de seu mentor sobre o São Paulo Futebol Clube, campeão paulista daquele ano. Para entender o

Revista AL TERJOR

Grupo de Estudos Alterjor:Jornalismo Popular e Alternativo (ECA-USP)

Ano 10 Volume 02 Edição $22 \quad$ Juho- Dezembro de 2020

Avenida Professor Lúcio Martins Rodrig̉ues, 443, Cidade Universitária, São Paulo, CEP: 05508-020 


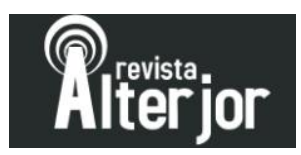

que o cronista queria dizer em sua derradeira mensagem, que fazia menção a um certo "Dançarino", o jovem percorre caminhos do futebol paulista na véspera da Copa de 1958.

Com isso, não só conhece mais sobre o vitorioso time composto por Poy; De Sordi e Mauro. Dino Sani, Vitor e Riberto; Maurinho, Amauri, Gino, Zizinho e Canhoteiro, além do reserva Sarará. É uma viagem em busca da imaginação e das condições históricas que levaram o técnico húngaro Bela Guttmann a mudar a cara do futebol brasileiro.

"O Dançarino e o Húngaro" é o segundo romance de Rafael Duarte Oliveira Venancio, escritor conhecido por sua série microcontos de futebol. Utilizando um estilo inspirado no estadunidense de ascendência madeirense John dos Passos, bem como nos cronistas esportivos brasileiros, o resultado aqui é um livro envolvente para quem ama ou desconhece o futebol, para quem é fanático ou rival do clube são-paulino e, até mesmo, para quem ama uma boa contação de história - atualmente chamada de storytelling - inspirada em fatos reais (VENANCIO, 2019b).

Além disso, no mencionado pós-doutorado, uma das propostas era atualizar essa fórmula. Com isso, o presente autor criou a série radiofônica de 12 peças sonoras denominada Seleção Paulista dos Craques de Outrora. Esta série foi escrita pelo autor utilizando sua ideia de "processo estoricizante", ou seja, buscar um fato histórico e torná-lo estória através de storytelling. Um craque e um clube de futebol paulista são escolhidos e possuem sua história transformada em estória por um personagem na forma de monólogo ou solilóquio radiofônico.

Este personagem, que é o agente da estória, é uma espécie de mascote sonoro do clube de futebol escolhido. Isso é uma influência clara da experiência do Show de Rádio de Estevam Sangirardi.

Tendo em vista a quarentena e o distanciamento social em São Paulo-SP na pandemia da COVID-19 em vigor no $1^{\circ}$ semestre de 2020, Seleção Paulista dos Craques de Outrora precisou não ser apenas escrito, mas também gravado pelo autor em sua casa. Assim, ele além de fazer sua própria voz (a voz do "storyteller"), ele teve que ser a voz de 12 mascotes sonoros.

Isso só foi possível através do desenvolvimento daquilo que aqui denominamos de "prosódia tecnológica", ou seja, a técnica de produção de áudio a partir da 


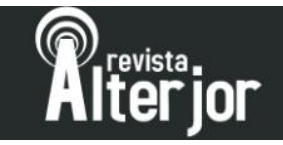

manipulação da onda sonora através da edição digital de áudio. Utilizando o programa Adobe Audition, o presente autor pôde criar 12 vozes diferentes da sua a partir de sua performance, criando um one-man show no estilo de Eric Bogosian (2014), Chico Anysio e, até mesmo, o próprio Estevam Sangirardi.

Os programas radiofônicos de Seleção Paulista dos Craques de Outrora serão veiculados no programa Universidade 93,7 da Rádio USP FM, no Anchor e no YouTube no início do $2^{\circ}$ semestre de 2020, próximos da data de encerramento do mencionado pós-doutorado.

\section{Considerações finais}

O processo estoricizante pode ser visto enquanto uma capacidade de escrita e reconstrução onde os fatos da estória são os fatos históricos que o storyteller diretamente seleciona, interpreta e dá uma forma narrativa, mesclando estratégias jornalísticas, literárias e dramatúrgicas, que faz surgir o texto da estória.

Sua importância nos parece crucial para a vivência da história nos nossos dias. Basta ver o exemplo duradoro de Shakespeare que mencionamos anteriormente. Basta ver o impacto que Cornwell possui na cultura britânica de hoje. Vale lembrar das críticas que Nelson Rodrigues fez ao mundo das letras e do jornalismo no Brasil de um ontem que não é tão distante assim.

Em um país, onde jovens vivenciam a língua portuguesa apenas produzindo dissertações para passar no vestibular e artigos científicos para se formarem enquanto bacharéis nas faculdades, a fabulação perde cada vez mais espaço. Pior ainda. Quando os jovens desejam ler algo de ficção ou mesmo ficção histórica, buscam autores traduzidos tal como Bernard Cornwell.

O incentivo ao processo estoricizante não é interessante apenas para o jornalismo esportivo, que é a atividade temática principal do autor do presente artigo. $\mathrm{O}$ incentivo ao processo estoricizante é interessante para todos aqueles que desejam trabalhar a História com estórias.

Revista ALTERJOR

Grupo de Estudos Alterjor: Jornalismo Popular e Alternativo (ECA-USP)

Ano 10 Volume 02 Edição $22 \quad$ Julho- Dezembro de 2020

Avenida Professor Lúcio Martins Rodrig̉ues, 443, Cidade Universitária, São Paulo, CEP: 05508-020 


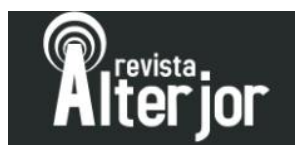

Claro que há os jornalistas que popularizam a história tais como Laurentino Gomes, Paulo Rezzutti, Eduardo Bueno, Pedro Dória, Luiz Octavio de Lima, entre outros. No entanto, eles, tal como Bernard Cornwell bem disse, não são contadores de histórias, storytellers, eles não tem um compromisso com a estória em si que se usa da História para existir.

É chegada a hora de formar cada vez mais storytellers brasileiros para termos sempre disponível uma forma alternativa de informar sobre os fatos históricos de nosso país. Talvez, possamos dizer, inspirados no que disse Nelson Rodrigues, há de formarmos cronistas que usem o processo estoricizante para "retocar o fato, transfigurálo, dramatizá-lo. [Dar] à estúpida e chata realidade um sopro de fantasia" (RODRIGUES, 1994, p. 11).

\section{Referências}

ASSIS, M. de. Crônicas escolhidas. São Paulo: Ática, 1994.

BENJAMIN, W. Magia e Técnica, Arte e Política (Obras Escolhidas v. 1). São Paulo: Brasiliense, 1994.

BOGOSIAN, E. 100 (monologues). New York: Theatre Communications Group, 2014.

CARDOSO, J. B. F.; SANTOS, R. E. "Humorísticos da TV brasileira: a trajetória do riso". Lumina. v.2, n.2. Juiz de Fora: UFJF, 2008.

CARR, E. H. Que é História?. Petrópilis: Paz e Terra, 2011.

CORAUCCI, C. Um Show de Rádio: A Vida de Estevam Sangirardi. São Paulo: A Girafa, 2006.

CORNWELL, B. "How Historical is Historical Fiction?" C. J. Adrien Official Website, 2019. Disponível em: https://cjadrien.com/2019/06/22/bernard-cornwell/.

JUNG, C. G. Os arquétipos e o inconsciente coletivo (Obra Completa vol. 9/1). Petrópolis: Vozes, 2019.

KING, J.; KING, W. "Shakespeare's History Plays". No Sweat Shakespeare, 2004. Disponível em: https://www.nosweatshakespeare.com/shakespeares-plays/playtypes/history-plays/

PAPEL, L. "Futebol e literatura: Professor reconta jogos das Copas do Mundo em 100 palavras". Globoesporte.com. Uberlândia: Globo Esporte Triângulo Mineiro, 2018. Disponível em: https://globoesporte.globo.com/mg/triangulo-mineiro/noticia/futebol-eliteratura-professor-reconta-jogos-das-copas-do-mundo-em-100-palavras.ghtml. 


\section{Retiejior}

RODRIGUES, N. A Pátria em Chuteiras: Novas Crônicas de Futebol. São Paulo: Cia das Letras, 1994.

VENANCIO, R. D. O. "Outros mundos do futebol: o exercício do isomorfismo linguístico na crônica esportiva". Estudos de Jornalismo e Mídia. v. 11, n.1, Florianópolis: UFSC, 2014.

Aposte no Mossoró: Uma estória esportiva no Rio de Janeiro dos anos 1930. Amazon: KDP, 2016.

KDP, 2017.

. Pilotos em uma Curva: Monólogo teatral sobre automobilismo. Amazon:

"Performance no gramado, poética no texto: A crônica e o conto de futebol como jornalismo esportivo alternativo". Revista Alterjor. v. 18, n. 2. São Paulo: CJE-ECA-USP, 2018.

Como escrever tirinhas de quadrinhos?: Um pequeno manual de roteiro $e$ storytelling. Amazon: KDP/To the Moon, 2019a.

. O Dançarino e o Húngaro: Uma estória são-paulina do futebol dos anos 1950. Amazon: KDP, 2019b.

. "Personagens, estórias, arquétipos e os mascotes sonoros: Estevam Sangirardi, Show de Rádio e a radiodramaturgia do futebol paulista", 2020, inédito no prelo. 